\title{
Centralized Wage Determination and Regional Unemployment Differences: The Case of Italy ${ }^{\dagger}$
}

\author{
Vincenzo Caponi ${ }^{\dagger \dagger}$ \\ Ryerson University, IZA, RCEA
}

May 13, 2009

\begin{abstract}
This paper presents a general equilibrium model of regional unemployment dispersion based on the Mortensen and Pissarides (1999) framework. The model economy presented here has centralized institutions, such as a single central government and central unions, but regional labor markets with differences productivity. The model assumes that unions dislike wage dispersion across regions and the government dislikes population imbalance across the regions. The set up of the model is used to interpret the economic features of the Italian economy between the mid seventies and the end of the past century. By means of calibration using Italian data collected in the year 2000 the paper shows that the model economy explains the important regional dualism between the North and the South of Italy in terms of unemployment. Moreover, the model indicates that the interaction between unions and the government also generates low wage rates in the high productivity regions accompanied by low unemployment rates, even when the Northern worker is the median worker that determines the unions policies.
\end{abstract}

JEL Classification: E240, J510, J600

\footnotetext{
${ }^{\dagger}$ I wish to thank Audra Bowlus, Marco Cozzi, Gueorgui Kambourov and Paul Klein for their support and useful comments on earlier versions of the paper. All remaining errors are mine.

${ }^{\dagger \dagger}$ Department of Economics, Faculty of Arts, Ryerson University, Toronto, Ontario, Canada. E-mail: vcaponi@ryerson.ca.
} 


\section{Introduction}

This paper presents a general equilibrium model of regional unemployment dispersion based on the framework of Mortensen and Pissarides (1999). The model economy is built to represent one country with centralized political and economical institutions, but with structural productivity differences across regions. One main feature of the model is that it takes into account the possibility that a worker might want to move from one region to another to exploit better economic conditions. Within the country the government does not have any power to stop people from migrating internally, as the freedom to move is assumed to be one funding right of the integrated political institution. Indeed, one main difference between internal migration and international migration is the inability of the government in the first case to put in place policies that can directly control the internal flow of people. However, the model assumes that the government dislikes the population imbalance that would be created by internal migration and acts to prevent it by setting policies that determine a disincentive to move. In the model only unemployed people looking for jobs can move from one region to another, therefore the government can prevent people from moving by equalizing the value of searching in each region, net of any possible cost of moving. To this end the government sets the level of unemployment benefits, paid to unemployed workers, and labor income taxes, collected from employed workers.

Other than a central government the other institutions in the model are the unions. Unions are also assumed to be centralized and responding to the interests of the median member. It is also assumed that unions dislike wage dispersion across regions, an outcome that would be determined if wages were left to be adjusted to the regional productivity, and acts consequently to set a uniform wage. Unions leave the right to manage the employment level to the firms and decide the wage rate unilaterally to maximize the welfare of the median employed worker. However, in doing so they also take into account how the government sets unemployment benefits and taxes.

One contribution of the paper is to present a model intended to stylize the main features of some of the largest continental European countries. In particular the presence of a centralized government and unions that aim at lowering the wage dispersion across regions while maintaining a balanced population seem to be consistent with the experience of countries such 
as Germany, especially after reunification, Spain, France and in particular Italy which also presents the highest degree of productivity dispersion, as measured by GDP per capita across regions. To quantitatively evaluate it, the model is calibrated to reflect relevant statistics from the Italian labor market around the year 2000. The main contribution of this paper is that it shows that a relatively simple model based on an extension to the popular Mortensen and Pissarides (1999) framework, can account for most of the unemployment imbalance between the Northern and Southern regions of Italy. Moreover, the model can also explain another puzzling feature of the Italian economy. Even in the presence of a high market rigidity ${ }^{1}$ Northern regions show the lowest levels of unemployment among European regions. Moreover, the North of Italy is one of the most productive regions in Europe while wages are relative low for European standards. This is in spite of powerful unions and the evidence that Northern workers are more influential in determining the unions policy that Southern workers (see Manacorda and Petrongolo (2005) on this point). The model and its calibration suggest that unions set a relatively low wage to avoid that an increase in labor income taxes will crowd out the gain in higher gross wages. This happens if the unemployment in the South grows too high and the government sets higher unemployment benefits and higher transfer of resources from the North to the South to prevent mass migration.

This paper relates to the literature on the dualism of the Italian economy. Even though Italy went from being one of the most geographically mobile labor markets to the most static among developed countries, the economic dualism that seemed to be the driving force behind the mass migration for more than a hundred years persisted, and as of today there are no signs of convergence. The persistence of these features for more than three decades suggests that the economy found a long-run equilibrium in which a wide economic gap and the absence of migration coexist at the expense of a wide unemployment gap.

Manacorda and Petrongolo (2005) claim that the most important feature for explaining the labor market dualism of the Italian economy is the centralized wage-setting mechanism. They

\footnotetext{
${ }^{1}$ Due to regulations imposed by unions and the government, Italy was reported by the OECD ${ }^{2}$ in 1999 to have the highest degree of labor market rigidity, as measured by employment protection legislation (EPL), among European countries. More recently, a set of reforms were passed by the Italian Parliament, in particular term contract legislations, which significantly relaxed the labor rigidity. However, this paper uses data collected around the year 2000 and aims at explaining the labor market in the last quarter of the twentieth century. The effects of the EPL relaxation will be evaluated in a policy experiment at the end of the paper.
} 
support their view by an empirical analysis in which they show first, that in the thirty years preceding 1998, wages steadily converged across regions in spite of an increasing unemployment gap, and, second, that wages seem to react more to market conditions in the North, rather than country wide.

In their view, this asymmetry in wage setting is mostly responsible for increased unemployment in Italy, which is uniquely driven by increased unemployment in the South. However, when we compare the Italian reginal rates of unemployment to other large European countries, for example France or Germany, we notice that the gap between the North and the South is at least partly due also to the low rates in the North of Italy accompanied by low real wages compared to productivity. Manacorda and Petronglo do not explain why, given that wages are set following the economic conditions in the North, they are significantly lower than in other continental European countries.

In their analysis, Manacorda and Petrongolo choose to treat migration as exogenous and assume that it does not exist. Faini, Galli, Gennari and Rossi (1997) suggest a solution to the empirical puzzle that shows the internal migration in Italy decreasing while unemployment differentials among Italian regions increase. They emphasize two major causes: high mobility costs and the inefficiencies in the job matching process. The inefficiencies in the job matching process stemmed from the government having a monopoly over job matching services. In the late 1990s the job matching process was successfully liberalized. However, the expected improvement predicted by Faini et al did not occur. As for mobility costs, it might be true that the North of Italy does not offer a very welcoming environment to newcomers making it costly to movers to settle in the Northern regions. However, while southern workers do not migrate to the North, the pressure of foreign workers to immigrate to the rich Northern regions is as high as in many other European countries. ${ }^{3}$

Compared to the previous literature, this paper assumes that the halt to internal migration was the wanted result of policies put in place by the government, that reacted to an increasing aversion toward internal mass migration started at the beginning of the seventies. This

\footnotetext{
${ }^{3}$ The foreign born population legally resident in Italy in 2001 was $2.3 \%$ of the total population, however, very unequally distributed across regions, in the North the average was about $3 \%$ while in the South less than 1\%. These percentages are low compared to other large European countries (France 5.6\%, Germany 8.9\%), but the large illegal immigration present in Italy, demonstrates that this due to very restrictive immigration policies rather than high costs to immigrate.
} 
increased aversion toward internal mass migration has been studied in other fields such as sociology and history, ${ }^{4}$ but it has never been analyzed in the economics literature, nor have been analyzed its important consequences. These policies, together with progressive centralization of the wage setting process occurred in the seventies, can explain the unemployment gap we observed in the thirty years between after the 1970 .

The paper is organized as follows: in the next section I present several statistics that document the Italian dualism focusing on the labor market. Section 3 presents a theoretical which is calibrated to match the data. The results of the calibration are presented in Section 4. Section 5 evaluates of the model. Section 6 concludes.

\section{Stylized facts of the Italian Economy}

Italy is one of the large western European countries together with Germany, France, the UK and Spain. Compared with these countries in 2000 Italy had similar but lower GDP per capita except for Spain, and even closer GDP per worker. ${ }^{5}$ At the same time, labor costs compared to productivity are lower in Italy than in any other country. Table 1 shows GDP per capita, in the first row, GDP per worker in second row and labor costs and direct pay for salaries and wages in the Industrial sectors in third and fourth rows, as reported by the regional statistics of Eurostat in non adjusted Euros. The fifth row of the table reports the ratio of the GDP of each country on the Italian GDP, the fourth row reports the ratios of labor costs, while rows six and seven report the ratios of labor costs and direct pay on GDP per worker respectively. Finally, row eight reports the unemployment rates in all countries.

The GDP per worker was only $9 \%$ higher in France than in Italy, basically the same in Germany and the UK while in Spain was almost 30\% lower. That is to say that the Italian productivity is not very far from other European countries. Yet, if we look at row six we see

\footnotetext{
${ }^{4}$ See Rella and Vadala (1984) for a literature review in sociology, or Cinanni (1974) for an example of the how the left parties and their cultural elites changed their view of the internal migration from positive to very negative. I also reproduce in Appendix a letter I received from Adalberto Minucci, who was the Major of Turin, the city that grew the most in the fifties and sixties due to the inflow of Southern immigrants, which shows the strong concern about the capacity of the city to receive more immigrants and suggests policies to halt these flows. It should be also noticed that the suggested policies were in fact adopted by the government later on.

${ }^{5}$ More recently in 2007 Spain surpassed Italy in terms of GDP per capita.
} 
Table 1: Labor Costs and Productivity in Selected European Countries in 2000

\begin{tabular}{lrrrrr}
\hline & Italy & France & Germany & Spain & UK \\
\hline \hline GDP per Capita & 20917 & 23726 & 25095 & 15653 & 26719 \\
GDP Per Worker & 56906 & 62334 & 56780 & 41177 & 56777 \\
Total Labor Costs & 32310 & 37579 & 45829 & 26496 & 44858 \\
Direct Pay (Wages) & 20917 & 23726 & 25095 & 15653 & 26719 \\
Ratio GDPxW/GDP Italy & 1 & 1.0954 & 0.9978 & 0.7236 & 0.9977 \\
Ratio Lab.Cost/Prod. & 0.5678 & 0.6029 & 0.8071 & 0.6435 & 0.7901 \\
Ratio Direct Pay/Prod. & 0.3676 & 0.3806 & 0.442 & 0.3801 & 0.4706 \\
Unemployment Rate & 10.6 & 10.2 & 7.9 & 13.9 & 5.6 \\
\hline \hline
\end{tabular}

Data: Regional Statistics, Eurostat.

that the Italian overall direct labor costs in the Industry is about $57 \%$ of GDP per worker, while in France is 60\%, 65\% in Spain and about $80 \%$ in Germany and the UK. Similarly, direct pay is in Italy about 37\% of GDP per worker, while is $38 \%$ in France and Spain and over $44 \%$ in Germany and the UK. In spite of similar productivity and lower labor costs Italy does not necessarily enjoy a lower unemployment rate. The last row shows unemployment rates in all countries and show that Italy performs very similarly to other countries. ${ }^{6}$

In spite of strong unions and strong and tight labor regulations, Table 1 clearly shows that labor costs in Italy are lower than in other European countries compared to labor productivity. However, if we look closer at the Italian economy, and in particular at its regional divide, a more interesting picture appears. Table 2 reports the same data reported in Table 1 but for five Italian regions for which Eurostat provides data. The five regions are representative of the divide between the North and the South of Italy. Those are Lombardia, one of the richest Northern regions, Emilia-Romagna another Northern region, Lazio, the only central region, which is also quite particular because it contains Rome, the capital of Italy. Then there are Campania, Sicilia and Sardinia all representative of the Southern economy.

First thing to notice from Table 2 is the great difference in terms of GDP per capita between the North, for example Lombardy, and the South, for example Campania. In Lombardy the GDP per capita is more than double that in Campania and is about 33\% higher than the Italian average. In contrast, in Campania, the region of Naples, is only $62 \%$ of the Italian average, while in Sicily is $63 \%$. In Sardinia arrives to a $74 \%$, though Sardinia is a much smaller

\footnotetext{
${ }^{6}$ It should be noted, however, that between 2000 and 2006 the unemployment rate in Italy decreased significantly to reach about $7 \%$. This change was due mainly to the introduction of new more flexible term contracts.
} 
Table 2: Labor Costs and Productivity in Selected Italian Regions in 2000

\begin{tabular}{lrrrrrrr} 
& Italy & Lomb. & Emil.-R. & Lazio & Camp. & Sicilia & Sard. \\
\hline \hline GDP per Capita & 20917 & 27807 & 26884 & 24238 & 13010 & 13256 & 15564 \\
GDP Per Worker & 56906 & 64936 & 61124 & 65270 & 47463 & 49024 & 49451 \\
Total Labor Costs & 32310 & 34494 & 33450 & 38743 & 29149 & 35620 & 31217 \\
Direct Pay (Wages) & 20917 & 21567 & 20403 & 24894 & 18595 & 22915 & 19817 \\
Ratio GDPxW/GDP Italy & 1 & 1.1411 & 1.0741 & 1.147 & 0.8341 & 0.8615 & 0.8690 \\
Ratio Lab.Cost/Prod. & 0.5678 & 0.5312 & 0.5472 & 0.5936 & 0.6141 & 0.7266 & 0.6313 \\
Ratio Direct Pay/Prod. & 0.3676 & 0.3321 & 0.3338 & 0.3814 & 0.3918 & 0.4674 & 0.4007 \\
Unemployment Rate & 10.6 & 4.4 & 4 & 11 & 23.7 & 24 & 20.6 \\
\hline \hline
\end{tabular}

Data: Regional Statistics, Eurostat.

region and less representative of the Italian South. Part of the difference can be explained by the uneven distribution of labor participation and unemployment. In fact, when we look at GDP per worker these differences are somewhat reduced. Lombardy results having a GDP per worker $14 \%$ higher than the Italian average while Campania 17\% lower. In any case there is still a gap of at least $20-30 \%$ between southern and northern regions. Looking at labor costs and compensations in rows three and four we can notice that they do not differ so much from region to region. This explains the results in rows six and seven where we can observe that the ratio of labor costs and compensations on productivity is quite different between northern regions and southern regions. Looking at row six we can see that labor costs absorb about $53-55 \%$ of the product per worker in the North, $59 \%$ in Lazio, while in the south the share goes up from the $61 \%$ of Campania to the $73 \%$ of Sicily. Similarly, labor compensations are $33 \%$ in the north, $38 \%$ in Lazio and between $39 \%$ and $47 \%$ in the south. Another interesting feature of the Italian divide is the net difference in the unemployment rates between north and south. Unemployment affects only $4 \%$ of the labor force in Emilia-Romagna and $4.4 \%$ in Lombardy, while more than $20 \%$ of the labor force in the three southern regions is unemployed.

Finally, it is also instructive to look at both the above tables together and compare especially the northern Italy with other European countries. Lombardy, for example has a GDP per worker that is higher than the average of all other European counrtries, while Emilia-Romagna is second only to Germany. Yet, labor costs and compensations are the lowest among all but Spain. In the following sections I will focus more on the Italian divided economy and in particular on the composition of its labor force. The few stylized facts presented will be also used 
in the calibration exercise at the end of the paper.

\subsection{Dualism of the Labor Force}

Here and in the reminder of the paper I use a mix of micro and macro data to describe some important features of the Italian labor markets. The source for micro data is the Survey on Household Income and Wealth (SHIW), conducted by the Bank of Italy. I use the year cross section in year 2000 of the longitudinal survey which comprises about 8,000 households $(24,000$ individuals), distributed over about 300 Italian municipalities. While the survey is longitudinal in principle, it presents a high degree of attrition and half of the sample is rotated in each wave, making it very difficult to exploit the longitudinal feature to conduct disaggregated analysis. SHIW is the only micro data available for Italy that contains detailed information about occupations, education and earnings of individuals together with other personal characteristics such as age, place of birth and place of residency. Other micro data exist for Italy that record information about labor force status, such as the survey on the labor force done by ISTAT, the national institute for statistics, but they do not contain any information about earnings of individuals. The macro, or aggregated data, I use come mostly from Istat and are based on several surveys or administrative data. I here use the aggregated figures that the institute publishes. I also use aggregated data from CRENOS, an institute on regional statistics based at the University of Sassari and from SVIMEZ, the institute for the development of the Southern economy. However, both these institutes re-elaborate data originally collected by ISTAT or administrative data from several ministries or other local governments' offices.

Tables 3 and 4 show the rates of employment and unemployment for men and women together and for men only in the South and the North of Italy. These tables are obtained from micro data from the SHIW. The population of reference is all the residents of age between 15 and 65 included. The SHIW asks respondents to indicate if they work, and if they do not work to specify why. In particular respondents are also asked if they are actively looking for a job for the first time or if they are actively looking for a job after having lost one (what is defined unemployed). Where actively looking for a job here it means to have make some serious effort in order to find a job in the last four weeks preceding the interview. Moreover, the survey also asks to the jobless interviewed that is not actively looking for a job if she was looking and 
stopped because it was to hard to find one. These people are the discouraged unemployed, and, particularly in the South and among women are a large fraction of the jobless people. Italy has always been considered a country with a significant problem of joblessness. However, Tables 3 and 4 show that the problem is in fact only in the South. The South experiences an unemployment rate of more than $21 \%$, while the North enjoys a very low rate of about $4 \%$.

Table 3: Labor Force Statistics (1) - Men and Women

\begin{tabular}{lrr}
\hline Employment/Unemployment Rates & North & South \\
\hline \hline Unemployment Rate (1) & 4.10 & 21.28 \\
Unemployment Rate (2) & 4.37 & 23.75 \\
Participation Rate (1) & 61.88 & 52.24 \\
Participation Rate (2) & 62.06 & 53.94 \\
\hline Employment Rate & 60.06 & 41.60 \\
\hline \hline
\end{tabular}

(1) First job seekers and unemployed searching for a job. (2)First job seekers and unemployed not searching because discouraged $+(1)$.

Data source: Survey on Household Income and Wealth (SHIW), Bank of Italy 2000. For a description of the data see Brandolini (1999)

Moreover, looking at the participation rates it can be observed that in the South the fraction of the working age population that is working or trying to find a job is 10 percentage points less than in the North. This results in only $40 \%$ of working age Southerners having a job as opposed to the $60 \%$ of Northerners ${ }^{7}$.

Table 4 shows that the difference in labor market participation between the two regions is exclusively due to women. Solely looking at men around $70 \%$ of the working age population intend to work in both regions, but again in the South only $58 \%$ work, while the others are unemployed.

Table 5 shows the exit rates from employment and unemployment. As reported in the last two rows these flows imply durations of employment of approximately 21 and 13 years for North and South, respectively, and 1.75 and 2.3 years, respectively, of unemployment. Therefore, higher rates of unemployment in the South are caused by a greater difficulty of finding a job and a higher probability of losing a job.

\footnotetext{
${ }^{7}$ The national average of about $53 \%$, which is substantially lower than the European average, is therefore mainly due to the South.
} 
Table 4: Labor Force Statistics (2) - Men

\begin{tabular}{lrc}
\hline Employment/Unemployment Rates & North & South \\
\hline \hline Unemployment Rate (1) & 3.32 & 19.44 \\
Unemployment Rate (2) & 3.53 & 21.80 \\
Participation Rate (1) & 72.07 & 70.31 \\
Participation Rate (2) & 72.23 & 72.45 \\
\hline Employment Rate & 71.47 & 58.04 \\
\hline
\end{tabular}

(1) and (2) defined as in Table 3.

Data source: SHIW, Bank of Italy 2000.

Table 5: Labor Force Statistics (3) Men and Women

\begin{tabular}{lcc}
\hline Change of Status, Annual rate & North & South \\
\hline \hline Employment to Unemployment & 0.96 & 2.10 \\
Exit from Employment & 4.63 & 7.78 \\
Unemployment to Employment & 29.19 & 15.05 \\
Exit from Unemployment & 57.25 & 43.61 \\
Out of the Labor Force to Employment & 6.42 & 5.04 \\
Out of the Labor Force to Unemployment & 2.73 & 6.72 \\
& & \\
Implied Average Duration of Empl. (years) & 21.60 & 12.85 \\
Implied Average Duration of Unempl.(years) & 1.75 & 2.29 \\
\hline \hline Status recorded in 2000 and 2001. \\
Data source: National Institute of Statistics (ISTAT), Labor Force \\
Statistics 2001.
\end{tabular}

Another important fact to connect with Tables 3 and 4 is the virtual absence of internal migration in Italy. Faini (1999) documents this fact for recent years. Figure 1 shows the flows of people between the South and the North of Italy, as well as from and to other countries. The figure shows that the rates referring to all people are very low.

The Italian North and the South do not differ only in terms of employment and unemployment, but also productivity is quite unevenly distributed. The following subsection presents the productivity divide. 
Figure 1: Population Flows

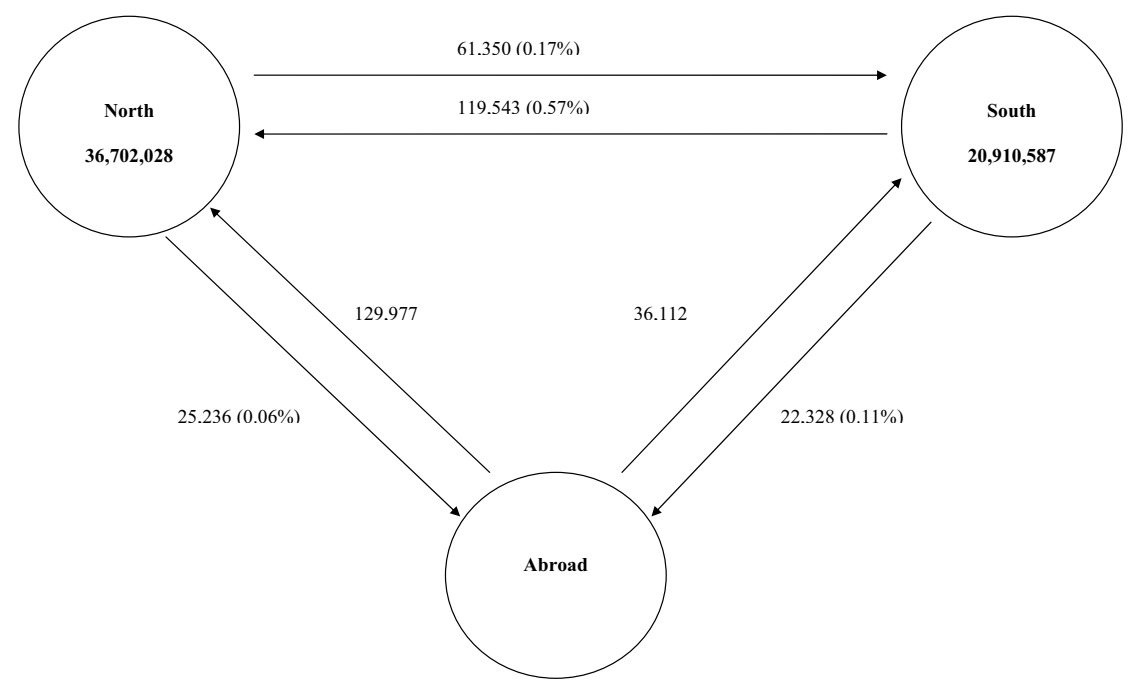

Data Source: ISTAT 1997.

\subsection{Productivity Differences}

Figure 2 and Figure D1 show GDP and capital per working unit ${ }^{8}$. These figures indicate that between 1970 and 1995 the productivity in the South has always been lower than in the North. As Figure D1 suggests this lower productivity of Southern labor is not induced by a lower amount of capital per unit. Indeed capital per unit in these 25 years has always been a bit higher in the South than in the North.

This is a peculiar fact. Given that productivity was lower in the South, why has there been so much investment, such that per capita units of capital are higher than in the North? Figure D2 shows capital per working unit in each sector of the economy. This picture seems to rule out the obvious explanation, that the government is the major investor in the South inflating the amount of capital per working unit. However during the seventies and eighties the government

\footnotetext{
${ }^{8}$ The measure of working unit is obtained dividing the total amount of hours worked by all workers by the typical working time, i.e. 40 hours per week.
} 
Figure 2: GDP per Working Unit - S/N Ratio

GDP per working unit: Ratio South/North

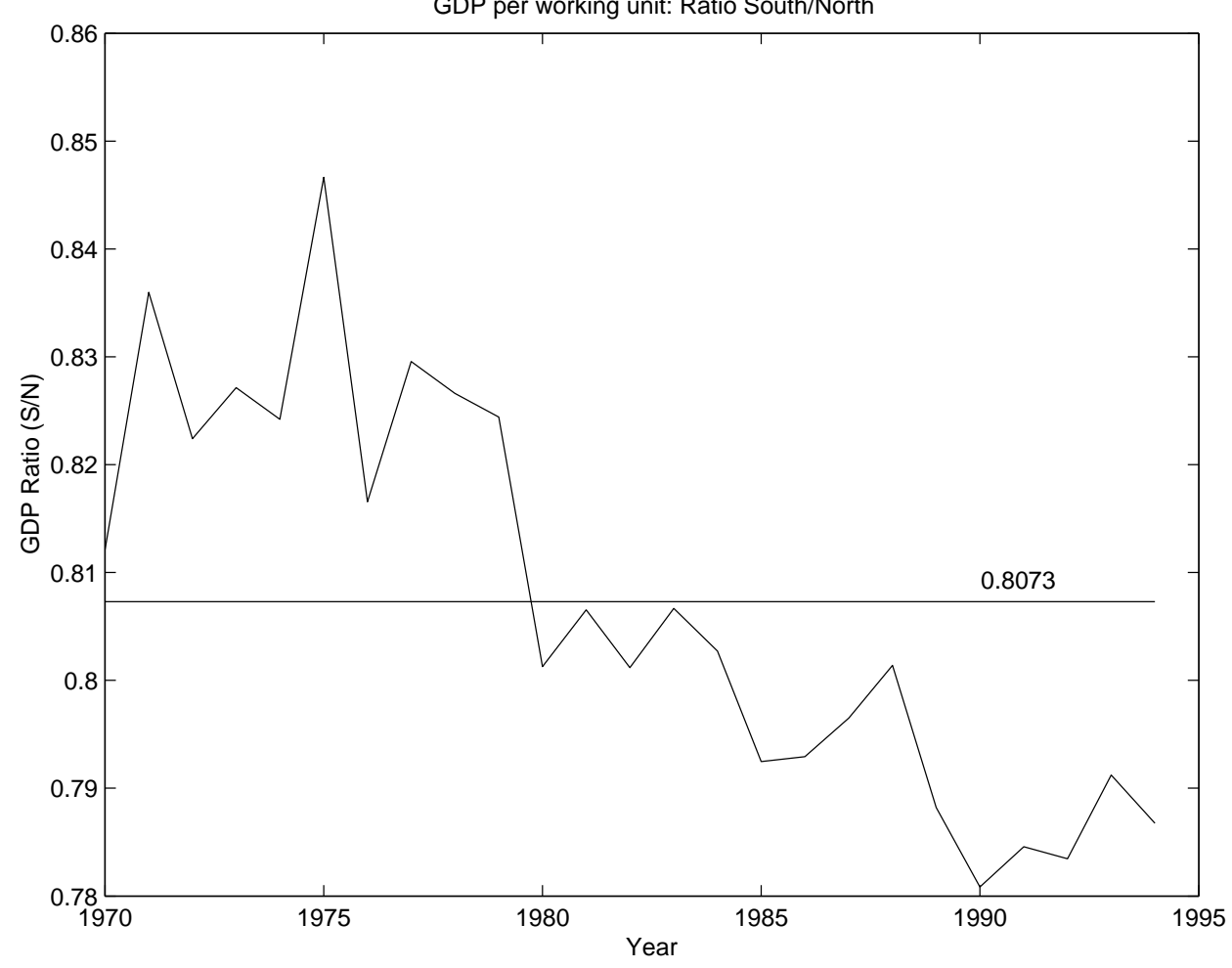

Data Source: Center for North South Economic Research (CRENOS). Regional Accounts.

owned large companies in all sectors of the economy. For example prior to becoming part of FIAT, Alfa Romeo and Lancia were under total control of the government which made large investments in the South specifically to help develop the regional economy ${ }^{9}$. Alfa Romeo was sold to FIAT in 1987. In the late 1980's and early 1990's, many other publicly owned companies were sold to the private sector starting what has been termed the privatization era. It is not surprising then that capital per working unit is higher in the South during the period before the privatization. Moreover, starting from the late 1980's capital per working unit in the industrial sector starts to decline in the South relative to the North.

Unfortunately data are not available for capital per working unit after 1995. However Figure D3 shows that the productivity of Southern regions did not substantially improve relative to the North.

\footnotetext{
${ }^{9}$ In the 1980's Alfa Sud was created, a line of Alfa Romeo cars produced in the Southern factories.
} 


\subsection{The Role of the Unions and the Government}

Two main assumptions will be introduced in the model economy about the behavior of unions and the government which need to be justified. I will assume that unions have a monopoly power to set the wage rate and that the same wage rate is paid to all workers across regions and I will assume that the government sets unemployment benefits and taxes with the objective to balance the budget and prevent souther workers to migrate to the North. Moreover I also assume that in the strategic interaction between unions and the government, the unions "move first" with the knowledge of what the government will do depending on the conditions of the economy. In other words, the unions see taxes and unemployment benefits as functions of the wage they set. In this section I motivate these assumptions.

\subsubsection{Wage Regional Equalization}

Much like other European countries, Italy is characterized by an important presence of unions in the economy. Table 6 shows, for different countries, two measures of union strength. The first number indicates how many employed workers are unionized (members of unions); the second how many workers are actually covered by union contracts. The first number for Italy is not exceptionally large if compared with other countries. However the second number shows the true strength of Italian unions: $82 \%$ of Italian employees are covered by wages contracted by unions.

\begin{tabular}{l|rr}
\multicolumn{3}{l}{ Table 6: Unionization in different Countries } \\
\hline Country & Union Density & Union Coverage \\
\hline \hline France & 9.0 & 95.0 \\
Finland & 81.0 & 95.0 \\
Belgium & 53.0 & 90.0 \\
Germany & 30.0 & 92.0 \\
Italy & $\mathbf{3 8 . 0}$ & $\mathbf{8 2 . 0}$ \\
Netherland & 25.5 & 81.0 \\
Norway & 58.0 & 74.0 \\
UK & 36.0 & 47.0 \\
Canada & 38.0 & 36.0 \\
United States & 16.0 & 18.0 \\
\hline Table from LaVoce, www.lavoce.it. & Data \\
OECD,1999 - Ebbinghaus e Visser 2000.
\end{tabular}


There are three major trade unions ${ }^{10}$ in Italy that represent the greater majority of union members ${ }^{11}$. These unions have various levels at which decisions are made from the council of the factory, where workers have the first nucleus of organization, to the "confederate" national council. By law there are three levels of bargaining between unions and Confindustria (the owners organization). The first level is national and confederate, i.e. at the "top" level of the unions, the second level is national by sector and the third is local by sector. Wages are first set taking into account the status of the economy ${ }^{12}$, at this stage a floor for wages is set. The second stage reflects the differences between sectors of the economy, while the third between firms within a sector.

It is only at the final stage of bargaining that a little differentiation of wages between Northern and Southern workers can be introduced. However, typically at this stage the margin for bargaining is very much reduced by the other two levels ${ }^{13}$.

To see if the unions are effective in equalizing wage rates across regions within each occupation I look at the wages earned by blue collars and office workers in different sectors of the economy. I use the data from the Survey on Household Income and Wealth (SHIW) done by the Bank of Italy from 1991 to 2006. In this time span the data were collected in the year 1991, 1993, 1995, 1998 and every two years thereafter until 2006, the latest year available. In total I keep the information coming from surveys conducted in eight different years. I use these data as repeated cross sections adjusting the monetary variable such that they are all expressed in year 2000 euros. I do this by deflating each year using the consumer price index series reported by the OECD statistics. The sample used is composed of men and women between 18 to 65 years old, working full time and full year as employees. Also, I consider only blue collars and office workers to keep the number of observations within each occupation reasonably large. The survey reports only yearly earnings, therefore hourly wages were constructed using the

\footnotetext{
${ }^{10}$ These three major unions are the Italian General Confederation of Workers (CGIL), the Italian Confederation of Labor Unions (CISL) and the Italian Union of Workers (UIL).

${ }^{11}$ More recently in a few sectors of the economy like the public sector, specifically school teachers, and in transportation, many workers organized themselves in different unions feeling that the three major ones were not representing their interests sufficiently.

${ }^{12}$ The first level is the most political. At this stage usually the government intervenes not only as a counterpart to the unions paying the salaries of public employees, but also as a moderator between unions and owners organizations.

${ }^{13}$ See Checchi (2000) for more on Italian unions.
} 
number of hours worked per week. Since the sample only contains full time full year workers to obtain the hourly wages the yearly earnings are divided by hours per week times 52 weeks worked in the year. Except for the information on the status of the employee (blue collar or office worker) and for the sector of activity the survey does not provide any other information to identify the occupation of workers. Therefore, occupation here is defined as the interaction between these two variables. So, for example, a blue collar working in manufacturing works in one occupation, a office worker working in the same sector works in another occupation and a blue collar working in real estate another.

Since productivity in the south is lower than in the north one would expect to see southern workers paid less than northerners. That, at least, in the absence of unions interested in equalizing wage rates. If however, unions are effective in equalizing the wage rates then this difference will not appear. In Table 7 the log hourly wages are regressed on a set of dummies representing each occupation (excluding agriculture), and a another set of dummies for south. The south dummies are the product of a dummy that take value 1 if the observation is for a southern worker and zero otherwise, and each occupation except for the south dummy relative to the intercept which takes value of one for all southern workers. The regression includes also dummies for education, so as to decrease the degree of heterogeneity within each occupation, and a quadratic function of actual experience. Actual experience is obtained by subtracting from age the age at the time of first job. In practice, having actual experience rather than potential experience, age minus schooling years, or age serves to control for the fact that southern workers start working at a later age. All these variable are also interacted to a south dummy to look at possible differences in returns to investments in human capital between the south and the rest of Italy. Moreover, dummies for each survey year except for 2000 were introduced although not reported in the table.

Looking at the results for men from the table is possible to see that the south dummy is not significantly different from zero for all the occupations except for those relative to the trade sector. Blue collars in trade earn about $5 \%$ less if they work in the south, while office workers in trade earn almost $9 \%$ less in the south. For all the other occupations, and in particular manufacturing which is the most important in terms of the number of employees, the earnings of southerners are statistically not different from the earnings of northerners. 
Moreover, generally the coefficient associated to the south dummy is very low and sometimes is even positive, which is further evidence that unions are indeed effective at equalizing the wage rates.

It is also interesting to see that the returns to education in terms of the wage rate are not different in the south and the north, all the south dummies associated to the levels of education are in fact small and not significantly different from zero. Also the returns to experience do not differ substantially between the north and the south, although here the coefficient on the south dummy shows a significant negative $0.43 \%$. In other words, while each additional year of experience increases the earnings of a northern worker by about $2.5 \%$, for a southern worker the increment is only $2 \%$. One reason that could justify this difference could be the fact that southerners are more likely to experience unemployment spells during the working life. As such, the measure of experience adopted here over estimates the actual experience of southern workers more than the experience of northern workers.

For women the picture looks very similar. One notable difference is that office workers in manufacturing earn about $11 \%$ less if they are in the south than if they are in the north, and the difference is significant. The difference in trade is also stronger than for men southern workers earning $14 \%$ less than northern workers.

Table 8 presents a set of tests on the joint significance of the south dummies. The first row tests the null hypothesis that all the south dummies are not significant, hypothesis that is rejected for men and women. The second row tests the joint significance of all the occupations and excluded education and experience. The test is now rejected only for men at $5 \%$ confidence level, but not at $1 \%$ and is not rejected for women at any conventional level of confidence. Finally, the last row tests the joint significance of the south dummies for all the occupations except for the occupations in the trad sector, and is not rejected for both sexes.

\subsubsection{Public Transfers}

There is evidence that the function of the government in Italy has been to transfer resources from the richer Northern regions to the poorer Southern regions. Table 9 presents this evidence. It can be noted that the central government spends more per capita in the South than in the North of Italy. Local regional governments are more responsive to the local conditions of the 
Table 7: Log Nominal Wages by Sector

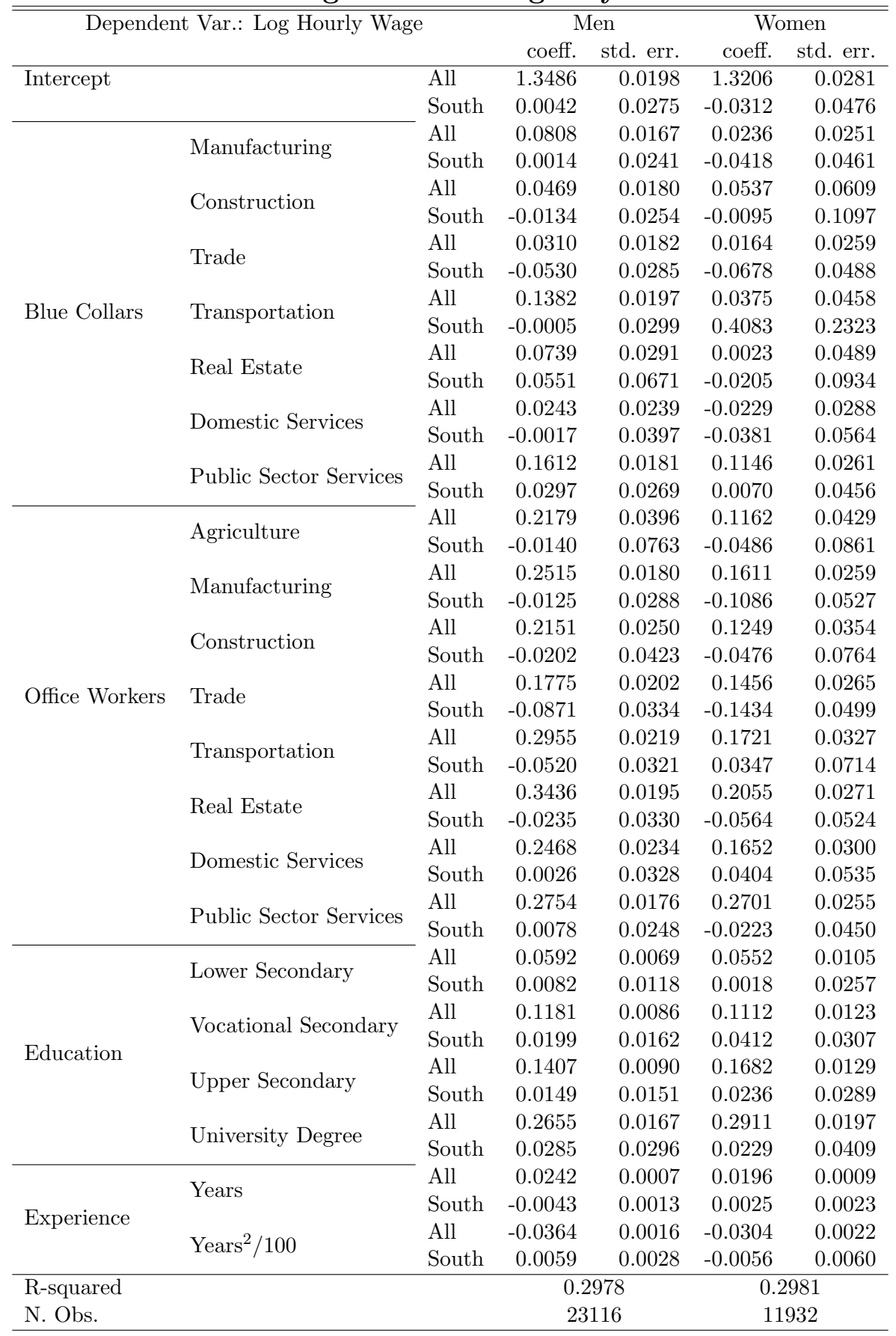

economy because of their (very little) autonomy in collecting resources and deciding the level of expenditure, so that the North spends more per capita than the South. Overall the total public expenditure per capita is higher in the North than in the South. However, two things 
Table 8: F-Tests on South Dummies Restrictions

\begin{tabular}{lllrr}
\hline \hline & \multicolumn{2}{c}{ Men } & \multicolumn{2}{c}{ Women } \\
Restrictions (variables set to zero) & F-statistic & p-value & F-statistic & p-value \\
\hline All South Dummies & 9.3021 & 0.0000 & 2.8507 & 0.0000 \\
All Southern Occupations & 1.8238 & 0.0136 & 1.0611 & 0.3844 \\
Selected Southern Occupations* & 0.9720 & 0.4893 & 0.3407 & 0.9956 \\
\hline
\end{tabular}

are clear from the table: 1) the central governments is transferring resources from the North to the South; 2) total public expenditure in the South represents a much larger proportion of GDP than in the North.

Table 9: GDP and Public Expenditure per capita: year 2000

\begin{tabular}{lcc}
\hline & North* $^{*}$ & South \\
\hline \hline GDP & $23,850.3$ & $13,584.2$ \\
Central government & 992.9 & 1255.8 \\
Regions & $2,442.2$ & $2,017.6$ \\
Total & $3,435.1$ & $3,273.4$ \\
\hline \hline *The definition of North excludes Lazio. \\
\multicolumn{3}{c}{ Source: SVIMEZ (2001), Table 23. }
\end{tabular}

In Italy there is not a well established policy that provides unemployment benefits to jobless workers. However, it seems reasonable to assume that the transfers from the central governments to the Southern regions have the indirect effect of financing unemployment spells. In fact there may be several ways in which resources from the general Southern population are diverted to unemployed workers. Perhaps the most important is intra-family redistribution. Unemployed workers in Italy, and particularly in the South, are mainly young and living with parents. In this case, families often bear the cost of having a jobless member. These families are often the target of general social programs that can improve their ability to care for its members. Table 10 presents some evidence consistent with this explanation. Using data from the SHIW I look at how the labor force status of an individual determines the probability that the family of the individual receives transfers from some level of the government (Central, Regions, Cities or other government agencies such as the national health system). The dependent variable in the estimated probit model in the table is a dummy variable that takes value equal to one if the family of the individual receives transfers for any reason and zero if it does not. One 
of the reasons to receive transfers is also being unemployed and receive some form of direct assistance. However, as mentioned before, this form of assistance is, at least formally, minimal. In fact, only about $2 \%$ of the unemployed in the survey declare to receive unemployment compensation. The explanatory variables are four dummies for four different cases of labor force status all alternative to being actively working (the intercept). I also add age and age squared, where age is the actual age minus 25 , so that the probabilities and the marginal effects can be read as for a 25 year old. The table clearly shows that being unemployed significantly increases the probability of the family receiving transfers from the government. Although the causal relationship to infer from the table is not obvious, it is clear that those families with unemployed members can count on the government for more support than others. The probability that an average person who works receives transfers is about $4.40 \%$ for men and $5.69 \%$ for women, as can be seen from the coefficient on the intercept. ${ }^{14}$ This probability is about $8 \%$ higher for men and $6 \%$ for women if the person is unemployed. The only other factors that increase the probability to receive transfers are being on welfare, and being a student. These two characteristics are the most obvious to justify the intervention of the government with transfers, nevertheless, transfers are even more probable to go to unemployed persons.

To address the complexity of the mechanism that guaranties that transfers will sustain the unemployment spells of unemployed workers, as the table above suggests, is beyond the scope of this paper. It is however important to know that, despite the absence of formal policies of unemployment benefits, unemployed can count on the generosity of government in a way or another. Most probably through the mediation of families as well. In the following sections, as a necessary simplification, I model these transfers as unemployment contingent income paid to unemployed workers.

\section{The Model}

There are two distinct labor markets geographically determined, characterized by different productivity values. Unemployed workers can decide to leave the market in which they are

\footnotetext{
${ }^{14} P(x \leq-1.7065)=0.440$ assuming $x \sim N(0,1)$.
} 
Table 10: Probability of Government Transfers

\begin{tabular}{|c|c|c|c|c|}
\hline \multirow{2}{*}{$\begin{array}{l}\text { Dep. Var. gov. Transfers } \\
\text { Variable }\end{array}$} & \multicolumn{2}{|c|}{ Men } & \multicolumn{2}{|c|}{ Women } \\
\hline & Probit Coeff & Av. Marg. Eff. & Probit Coeff & Av. Marg. Eff. \\
\hline \multirow[t]{2}{*}{ Intercept } & -1.7065 & & -1.5811 & \\
\hline & $(0.0308)$ & & $(0.0326)$ & \\
\hline \multirow[t]{2}{*}{ Unemployed } & 0.6514 & 0.0810 & 0.4380 & 0.0601 \\
\hline & $(0.0396)$ & $(0.0315)$ & $(0.0469)$ & $(0.0155)$ \\
\hline \multirow[t]{2}{*}{ Home Makers } & -0.0462 & -0.0057 & 0.0653 & 0.0090 \\
\hline & $(0.4644)$ & $(0.0022)$ & $(0.0319)$ & $(0.0023)$ \\
\hline \multirow[t]{2}{*}{ Retirees } & -0.2710 & -0.0337 & -0.1600 & -0.0219 \\
\hline & $(0.0632)$ & $(0.0131)$ & $(0.0713)$ & $(0.0056)$ \\
\hline \multirow[t]{2}{*}{ In Welfare } & 0.2674 & 0.0332 & 0.1139 & 0.0156 \\
\hline & $(0.0941)$ & $(0.0130)$ & $(0.0848)$ & $(0.0040)$ \\
\hline \multirow[t]{2}{*}{ Student } & 0.5345 & 0.0664 & 0.4544 & 0.0623 \\
\hline & $(0.0563)$ & $(0.0259)$ & $(0.0576)$ & $(0.0160)$ \\
\hline \multirow[t]{2}{*}{ Age } & 0.0093 & 0.0012 & 0.0154 & 0.0021 \\
\hline & $(0.0035)$ & $(0.0004)$ & $(0.0034)$ & $(0.0005)$ \\
\hline \multirow[t]{2}{*}{$\mathrm{Age}^{2} / 100$} & -0.0164 & -0.0020 & -0.0503 & -0.0069 \\
\hline & $(0.0103)$ & $(0.0008)$ & $(0.0097)$ & $(0.0018)$ \\
\hline \multirow[t]{2}{*}{ Average Probability } & & 0.0663 & & 0.0735 \\
\hline & & $(0.0364)$ & & $(0.0256)$ \\
\hline LogLikelih & & 379 & & \\
\hline N. Obs. & & 0780 & & 354 \\
\hline
\end{tabular}

originally located and search in the other market. They can move at any time while unemployed, but they pay a cost $\mathrm{cm}$ if they relocate. Firms open vacancies whenever they want to fill a job. Keeping a vacancy open implies some cost $p_{i} c$, proportional to productivity $p_{i}$ specific to markets.

The rate at which unemployed workers and open vacancies meet is regulated by a meeting function $m(v, u)$ that depends on the number of unemployed workers and vacancies in each market at the time. Once there is a meeting firms observe the worker specific productivity shock $\alpha$, and decide if the candidate is suitable for the job, i.e. if $\alpha$ is above the reservation value. If so, a match is created and the wage $w$ is paid to the worker. After a match is created a worker is hit by productivity shocks that arrive at a rate $\lambda$. The productivity shock changes the worker specific productivity $\alpha$. Firms fire workers whenever their productivity decreases below the reservation value.

Finally, I assume that the wage is set by the unions and is the same for all workers regardless 
of their market. Unions are assumed to represent all workers in the economy and weight all workers equally. Decisions within unions are assumed to be taken by majority rule. Therefore, the role of unions is to set the wage so as to maximize the expected utility of the median worker in the economy. Moreover workers pay a tax collected by the government to finance unemployment benefits paid to unemployed workers. The role of the government is to prevent unemployed workers from migrating from the South to the North. The government does this by setting unemployment benefits at such a level that the value of unemployment in the lower productivity region plus the cost of moving equals the value of unemployment in the higher productivity region. Also it sets the tax rate in order to collect the taxes necessary to balance the budget after paying the unemployment benefits.

Following Mortensen and Pissarides (1999) the meeting function is written as follows

$$
m_{i}\left(v_{i}, u_{i}\right)=m\left(1, \frac{u_{i}}{v_{i}}\right) v_{i} \equiv q_{i}\left(\theta_{i}\right) v_{i} \text { where } \theta_{i}=\frac{v_{i}}{u_{i}}
$$

Given the meeting function the ratios at which vacancies are filled can be defined as follows

$$
q_{i}^{f}=q\left(\theta_{i}\right) \int_{R_{i}}^{\bar{\alpha}} d F(\alpha)
$$

where $\bar{\alpha}$ is the upper limit of the shock distribution and $R_{i}$ is the reservation value. The ratio at which unemployed workers find a job is instead given by

$$
q_{i}^{w}=q\left(\theta_{i}\right) \theta_{i} \int_{R_{i}}^{\bar{\alpha}} d F(\alpha)
$$

\subsection{Value of a match to an employer}

The value of a job to an employer depends on the productivity specific to that match. The productivity is the product of the shock $\alpha$ and the market specific productivity parameter $p_{i}$. Therefore the value of the job is

$$
r J_{i}(\alpha)=p_{i} \alpha-w+\lambda \int_{R_{i}}^{\bar{\alpha}}\left[J_{i}(x)-J_{i}(\alpha)\right] d F(x)-\lambda F\left(R_{i}\right) J_{i}(\alpha) .
$$

That is, the expected discounted gain in the value of a match is given by the difference between the productivity and wage paid by the employer, plus the expected change in value. Note that 
here the wage is not a function of $\alpha$ since it is determined by the unions and is the same for all workers.

The above asset equation describes the value of a match that is created. Therefore it is assumed that $\alpha$ is greater that the reservation value $R_{i}$ determined by the employer. However in order to decide to open a vacancy a firm must consider the expected value of a match before the productivity shock is realized. Therefore, taking the expectation of equation $(3)^{15}$

$$
r J_{i}^{e}=p_{i} \alpha_{i}^{e}-w-\lambda F\left(R_{i}\right) J_{i}^{e},
$$

where the superscript $e$ indicates the expectation conditional on $\alpha$ being greater than $R_{i}$

$$
\alpha_{i}^{e}=\int_{R_{i}}^{\bar{\alpha}} \alpha d F(\alpha)
$$

\subsection{Value of a match to a worker}

The value of a match to a worker is determined by the following asset equation

$$
r W_{i}=w(1-t)+\lambda F\left(R_{i}\right)\left[U_{i}-W_{i}\right]
$$

where $t$ is a proportional tax collected by the government in order to provide unemployment benefits.

\subsection{Value of a vacancy and of unemployment}

The value of setting a vacancy to an employer is ${ }^{16}$

$$
r V_{i}=-p_{i} c+q_{i}^{f}\left[J_{i}^{e}-V_{i}\right]
$$

While the value of being unemployed for a worker is

$$
r U_{i}=b+q_{i}^{w}\left[W_{i}-U_{i}\right]
$$

\footnotetext{
${ }^{15}$ Derivation in Appendix A.

${ }^{16}$ See Appendix A on how to derive this equation.
} 
where $b$ represents unemployment contingent income. The value of a vacancy is therefore equal to the probability of finding a worker for a firm, times the value of an initial job match less the value of the vacancy itself, minus the cost of keeping a vacancy open. The rate at which a worker is found is regulated by the meeting function and is proportional to the portion of vacancies posted in the same location. The value of unemployment is given by the unemployment benefits the unemployed worker receives plus the expected gain of searching, i.e. the expected value of a match discounted by the rate at which the worker matches with a firm.

\subsection{Wage Setting}

In this section the major features of the model are introduced. As stated above it is assumed that the wage is set by the unions following a right-to-manage model in which unions decide a take it or leave it wage rate and firms decide the level of their employment. The wage that is the same for all workers in both regions. In other words the unions set a wage that is then imposed by law on everybody. This wage setting is the common way wages are actually determined in Italy where the three major unions meet with representatives of firms and set a wage that is imposed on every worker with the same tenure, skill level and sector of the economy. Another important point to note is that unions do not set the wage only for unionized workers but for everyone. Once the wage is set by unions it does not matter if a worker is unionized or not, he is offered the contract wage.

As a simplification I assume that all workers are unionized and therefore the wage is set by the median worker so as to maximize the value of his match. Therefore:

$$
w=\operatorname{argmax}\left\{W^{m}\right\}
$$

where $W^{m}$ is the value of a match to the median worker. In the model the median worker is the one that works in the region with higher employment. This is because, given that the wage is equal for everyone, the value of a match to a worker is the same for all employees within one region, while across different regions it can be different because the probability of finding a job after being fired is different. 


\subsection{Government}

The government plays an important role in the model. The actions of the government are subject to the constraint of balancing the budget through fixing taxes and unemployment benefits so as to avoid migration. Its program is then described by the following

$$
\begin{aligned}
& U_{i}=U_{j}+c m \\
& b\left(\gamma_{i} u_{i}+\gamma_{j} u_{j}\right)=t w\left(\gamma_{i}\left(1-u_{i}\right)+\gamma_{j}\left(1-u_{j}\right)\right),
\end{aligned}
$$

where $\mathrm{cm}$ is a cost of moving faced by the unemployed worker from region $j$ that would like to migrate to region $i$, assuming that in region $j$ the value of unemployment is lower than in region $i$.

\subsection{Solving the Model}

In order to obtain the variables of interest as functions of the parameters of the model a few stationary equilibrium conditions need to be imposed. First, the value of a vacancy in each region is equal to zero, the so-called free entry condition which implies that the employers open vacancies until there is an expected profit. Creating new vacancies lowers the expected profit of employers by making the market tighter (increasing $\theta$ ), this process continues until the market is tight enough to insure expected profits are equal to zero for all the employers.

An additional condition is the hiring/firing condition. This in turn gives the reservation value of the idiosyncratic shock. Since the distribution of shocks does not change in each period, the decision of hiring and firing a worker made by the firm is based on the same threshold value. In other words the firm wants to keep a worker as long as she has an idiosyncratic

productivity that is higher than the threshold value. This is true at the meeting when the decision to hire is made, and thereafter when the decision of firing may be made.

The first condition translates in the following equation

$$
J_{i}^{e}=\frac{p_{i} c}{q_{i}^{f}} .
$$

While the second condition can be expressed as follows 


$$
J_{i}\left(R_{i}\right)=0
$$

Substituting equation (4) and equation (3), respectively, in equation (12) and equation (13) it is possible to obtain the values of market tightness and the reservation shock value as functions of the wage: $\theta_{i}(w)$ and $R_{i}(w)$.

Finally to obtain the wage I substitute $\theta_{i}(w)$ and $R_{i}(w)$ into $\theta$ and $R_{i}$ in equation (6), where here $i$ refers to the north. Then I maximize the value of a match to a Northern worker in equation (6) with respect to $w$, taking the government problem as a constraint. Although in principle the model should have closed form solutions, the maximization problem is too involved for being solved analytically and numerical solutions must be used, hence an evaluation of the properties of the model will be done by simulating alternative scenarios with the calibrated parameters. The following section explains how the calibration is done.

\section{Calibration}

To test the quantitative implications of the model the first step is to choose the functional forms for the meeting function and for the shock distribution. For simplicity I choose a Cobb-Douglas functional form for the meeting function

$$
m(u, v)=u^{\eta} v^{1-\eta} \rightarrow q(\theta)=\theta^{-\eta},
$$

and a uniform function for the shock distribution with mean fixed to 1 , and variance $s$. As for the values for the parameters, I fix the interest rate $r$ to .01 as the model period is a quarter, and the elasticity of the meeting function to .5 following Blanchard and Diamond (1989) and Blanchard and Diamond (1990) who provide empirical evidence for the functional form and the value of the elasticity for US data. I also normalize the value of productivity in the North to 1 . The population shares $\gamma_{i}$ 's are set to 0.68 for the North and 0.32 for the South. Moreover, I need to choose values for the recruiting $\operatorname{cost} c$, for the variance of shocks $s$, the arrival rate of a shock after a match is created $\lambda$ and the productivity in the South. These parameters are found by calibrating the model to match appropriate data moments. 
Table 11: Calibration (1) - Parameters

\begin{tabular}{lcc}
\hline Parameter & Normalized & Fixed by Calib. \\
\hline \hline Structural Prod. North $p_{N}$ & $\sqrt{ }$ & \\
Structural Prod. South $p_{S}$ & & $\sqrt{ }$ \\
Shock arrival rate $\lambda$ & & $\sqrt{ }$ \\
Variance shock distrib. $s$ & & $\sqrt{ }$ \\
Recruiting cost $c$ & & $\sqrt{ }$ \\
Population Shares $\gamma$, and $1-\gamma$ & & \\
Interest rate $r$ & $\sqrt{ }$ & \\
Duration elasticity $\eta$ & $\sqrt{ }$ & \\
Cost of moving $\mathrm{cm}$ & $\sqrt{ }$ & \\
\hline \hline
\end{tabular}

Table 11 shows how the parameters of the model are chosen. The cost of moving is unobservable and is a difficult parameter to choose. I fix the parameter to 5 and perform a sensitivity analysis to assess how sensitive the results are to this parameter. The parameters that are set by calibration satisfy the moment conditions in Table 12. These moments are the ratio of the Southern productivity to the Northern productivity in row 1, the durations of a job spell in the North and in the South in rows 2 and 3 and the unemployment rate in the North (row 4). The second column in Table 12 shows the functional forms derived from the model, while the right column shows the data values of the moments.

\section{Table 12: Calibration (2) - Data Moments}

\begin{tabular}{llr}
\hline Moment Description & Moment Function & Data Value \\
\hline \hline Ex=post Productivity Ratio S/N & $\frac{p_{S}\left(R_{S}+1+\sqrt{3} s\right)}{p_{N}\left(R_{N}+1+\sqrt{3} s\right)}$ & 0.8073 \\
Employment Duration in the North (yrs.) & $\frac{1}{4 \lambda F\left(R_{N}\right)}$ & 21.6 \\
Employment Duration in the South (yrs.) & $\frac{1}{4 \lambda F\left(R_{S}\right)}$ & 12.85 \\
Unemployment Rate in the North (\%) & $\frac{\lambda F\left(R_{N}\right)}{q_{N}^{w}+\lambda F\left(R_{N}\right)}$ & 4.37 \\
\hline
\end{tabular}

Table 13 reports the values the parameters that satisfy the calibration conditions. The structural productivity in the South is about $77 \%$ that of the North. The shock arrival rate is set by the calibration to about 0.07 , while the variance of the shock distribution is set to 0.226. Since the uniform distribution is centered at 1 , this implies a value for the lower and upper bounds of the distribution of 0.61 and 1.39, respectively. That is, individuals can expect 
Table 13: Calibration (2) - Parameter Values

\begin{tabular}{l|cc}
\hline Parameter & North & South \\
\hline \hline Structural Prod. $p_{i}$ & 1 & 0.771 \\
Population Shares $\gamma$, and $1-\gamma$ & 0.68 & 0.32 \\
Shock arrival rate $\lambda$ & 0.0694 \\
Variance shock distrib. $s$ & 0.2259 \\
Recruiting cost $c$ & 48.97 \\
Interest rate $r$ & 0.01 \\
Duration elasticity $\eta$ & 0.5 \\
Cost of moving $c m$ & 5 \\
\hline
\end{tabular}

to have a productivity between these two values with equal probability. The recruiting cost is 48.97, which is a relatively high value if compared to the productivities.

Table 14 shows the result of the calibration. The moments that are not targeted are the unemployment in the South and the unemployment durations in the South and the North. Unemployment in the South is higher than in the data, reported to be 23.75. However, there is evidence that unemployment could be higher than indicated by standard statistics especially in the South. Standard statistics, following the International Labor Organization (ILO) definition, identify unemployed an individual who is not working and actively searched for a job in the one month prior to the interview. In Italy, and particularly in the South, the average period of unemployment is over two years long; as such it may be reasonable to expect that active searching actions may be more spaced in time than one month. Viviano (2002) provides some evidence that this is the case. Re-estimating the unemployment rate for the South using 6 months for the frequency for job searching rather than the 1 month used by ILO he finds that the unemployment rate in the South is $26.9 \%$ rather than $23.75 \%$.

In terms of the duration of unemployment the model does not perform as well as it does with respect to Southern unemployment. However, it should be noted that the set of data used to derive these moments is different from the data used for unemployment rates. Therefore, there may be some discrepancies between the data.

Prior to looking at the other results from the calibration it is useful to give an interpretation of the obtained parameter values. Returning to Table 13 it is striking that the recruiting cost is very high compared to the productivity averages. The reason why this arises must be found in 
Table 14: Calibration (3) - Variables Values $\mathbf{c m}=\mathbf{5}$

\begin{tabular}{|c|c|c|c|c|}
\hline \multirow[b]{2}{*}{ Endogenous variables } & \multicolumn{2}{|c|}{ Data Moments } & \multicolumn{2}{|c|}{ Model Predictions } \\
\hline & North & South & North & South \\
\hline "Rate of Unemployment & 4.37 & 23.75 & "4.37 & 26.92 \\
\hline Unemployment Duration (years) & 1.75 & 2.29 & 0.99 & 4.73 \\
\hline Employment Duration (years) & 21.6 & 12.85 & 21.6 & 12.85 \\
\hline Ex Post Productivity & $\mathrm{S} / \mathrm{N}$ ratic & 0.8073 & 1.07 & 0.86 \\
\hline Wage $w$ & \multicolumn{2}{|c|}{-} & \multicolumn{2}{|c|}{0.51} \\
\hline Taxes $t$ & \multicolumn{2}{|c|}{. } & \multicolumn{2}{|c|}{0.07} \\
\hline Unemployment Benefits $b$ & \multicolumn{2}{|c|}{-} & \multicolumn{2}{|c|}{0.29} \\
\hline
\end{tabular}

the zero vacancy condition, that is, the value of a vacancy must be equal to zero in equilibrium. Equation (7) implies that

$$
p_{i} c=q_{i}^{f} J_{i}^{e}
$$

That is, the cost of setting a vacancy must be proportional to the expected value of a match times the probability to form a match once the vacancy is set. Due to the prolonged duration of employment spells, particularly in the North, and the large difference between the expected productivity of a match and the wage, the value of a match to an employer is very high, hence the high vacancy cost.

A high vacancy cost is an indication that the Italian labor market is a very rigid one. As stated above, Italy is a country with very high Employment Protection Legislation. However, the model does not formalize these aspects of the Italian economy except for the wage setting process. Other rigidities induced by law might be related to strict regulations about the labor conditions of employees in their workplaces, the difficulty to start and end a business due to an excessive bureaucracy, taxes imposed by the government for starting a business or for hiring an employee etc...; all these rigidities are captured by the high cost of setting a vacancy. This reflects the reduced gain faced by the prospective employer due to the restrictions imposed by laws on her behavior once the match is created. Firing restrictions are also present in the Italian economy, however, they only exist for large companies that have at least 15 employees, while they do not bind for smaller companies, which are a large part of the Italian economy, and most importantly do not bind in the informal sector, which especially in the South represents 
a large share of the economy.

The arrival rate of a shock is calibrated to 0.0694 . This could also be considered low, which is clearly related to the long employment spells. In other words, once the match is created, the lower the arrival rate of shocks is the greater the probability that the match is not broken, i.e. the worker is not fired.

The structural productivity in the South is set at 0.77 , lower than the ex-post productivity. The ex-post productivity is the product of the structural productivity and the average conditional productivity of the working population. Given that in the South the structural productivity is lower than in the North, while the wage is the same, the reservation productivity level in the South is higher than in the North (0.74 in the North and 0.83 in the South). This implies that the workers average conditional productivity is higher than in the North; as such the structural productivity must be lower than the ex-post productivity. This suggests that workers in the South are actually more selected and therefore more productive individually than in the North. However, because of the structural productivity they do not produce as much as Northern workers.

Finally, the shock variance in the calibration determines the difference between the probabilities to be employed or fired, and therefore, given the productivity difference, the unemployment rates and employment durations. Together with the shock arrival rate, this parameter reflects the low degree of uncertainty present in the Italian labor market once a job is created.

\section{Model Evaluation}

Since the parameter indicating the cost of moving cannot be identified by calibration I fixed the value to 5 for the calibration and then performed sensitivity analysis in order to assess the importance of the parameter.

The sensitivity analysis presented in Table 15 suggests that unemployment rates are not very sensitive to the cost of moving. Changing the cost of moving to zero and 10 changes the value of unemployment benefits needed to equalize the values of unemployment, and therefore the taxes. However, it does not significantly change the employment and unemployment rates in both regions. 


\begin{tabular}{lrrrr}
\multicolumn{4}{c}{ Table 15: Sensitivity Analysis $\mathbf{- ~ c m = 0 ~}$} & to $\mathbf{1 0}$ \\
\hline & \multicolumn{2}{c}{$\mathrm{cm}=0$} & \multicolumn{2}{c}{$\mathrm{cm}=10$} \\
Endogenous variables & North & South & North & South \\
\hline \hline Rate of Unemployment & 4.28 & 26.13 & 4.46 & 27.73 \\
Unemployment Duration (years) & 0.97 & 4.57 & 1.00 & 4.90 \\
Employment Duration (years) & 21.77 & 12.92 & 21.43 & 12.76 \\
Ex Post Productivity & 1.06 & 0.85 & 1.07 & 0.86 \\
Wage $w$ & 0.500 & \multicolumn{2}{c}{0.503} \\
Taxes $t$ & 0.113 & 0.037 \\
Unemployment Benefits $b$ & 0.444 & 0.137 \\
\hline
\end{tabular}

If Southerners face a higher cost of moving then they need a lower compensation for their unemployment in order to remain in their own regions, therefore the unemployment benefits are lower and so are taxes. If the cost is instead very low, then unemployment benefits need to be higher.

\subsection{North to South Transfer of Resources}

One of the important implications of the model is that the joint policies of the government and unions determine a transfer of resources from the rich North to the poor South. When in a unified country there are regions that are economically lagging behind it is natural that the central government implements redistributive policies to improve the conditions of the poorer regions. In Italy, a big part of this redistribution is at the same time the cause and effect of the higher unemployment rate. Table 9, shows the per capita public expenditure done by the central government and by regional governments in the South and the North in comparison to their GDP. The central government spends about 3\% of that region's GDP in the North, while the fraction in the South is about 10\%. Considering total public expenditure those shares grow to $14.35 \%$ in the North and $24.62 \%$ in the South. Given the proportion of the populations in the two regions the figures reported in the table imply that each Italian pays about $15.21 \%$ of its share of produced GDP for providing public expenditure. Therefore, the Northern worker finances the Southerner with $0.86 \%$ of produced GDP.

The model predicts similar transfers of resources from the Northern workers to the Southern population. Fixing the cost of moving equal to 5, the model in Table 14 predicts that the North transfers about $66 \%$ of the taxes paid to the Southern economy. In fact the share of the taxes 
collected by the Northern economy that returns to Northern residents is given by

$$
\frac{b u_{N}}{w t\left(1-u_{N}\right)}=.338
$$

Therefore, the Northern worker collects about $2.43 \%$ of her income to transfer to the Southern economy. Since the income of the Northern worker is about $47 \%$ of the total share of GDP per worker produced in the North, the transfer of resources in terms of GDP is of $1.15 \%$. This is a similar figure to the $0.86 \%$ from the data.

\subsection{An Alternative Scenario: De-centralized Unions}

In this section I describe a situation in which the cost of moving is assumed to be very high such that unemployed workers are never willing to move from one region to the other and unions set wages regionally. This exercise is designed to show that the government and union policies of centralized wage setting and transfers from the North to the South can explain the exceptionally low unemployment rate in the North.

Table 16 shows the unemployment rates in the North and the South under this different scenario. The government here simply sets the unemployment benefits exogenously. These are set at the same level obtained above by calibration. It is possible to notice that unemployment in the North is 3 times higher than it was previously, while in the South the rate is lower. Northern workers now enjoy a higher wage rate, though the taxes they pay now are only slightly lower in terms of percentage and higher in absolute terms. In the South the unemployment rate is less than half what it was previously and is even lower than in the North, although only marginally. The difference in structural productivity is now completely transferred to the wage. The wage rate in the South is in fact about $77 \%$ of the wage in the North.

In this scenario, unions do not need to take into account the reaction of the government to the wage setting. Before unions were careful about setting a high wage because they knew it would increase unemployment in the South, and, consequently, the tax rate to finance the transfers implemented by the government. With higher tax rates, the after-tax wage could become lower. Keeping the wage rate low to avoid high unemployment rates in the South makes employers willing to employ more workers and leads to the low unemployment rate. In the scenario presented here unions are free to set the wage taking into consideration only the 
Table 16: Italy Divided

\begin{tabular}{lrr}
\hline Endogenous variables & North & South \\
\hline \hline Rate of Unemployment & 12.90 & 12.68 \\
Unemployment Duration (years) & 2.27 & 2.23 \\
Employment Duration (years) & 15.32 & 15.39 \\
Ex Post Productivity & 1.09 & 1.05 \\
Wage $w$ & 0.593 & 0.456 \\
Taxes $t$ & 0.071 & 0.091 \\
Unemployment Benefits $b$ & 0.029 & 0.029 \\
\hline
\end{tabular}

economic situation in the North.

\section{Conclusion}

This paper documents the government aversion toward internal mass migration that started to arise during the seventies, years in which ultimately the internal migration ceased. Although this fact has been studied in other fields such as sociology and history, it has never been analyzed in the economics literature, nor have been analyzed its important consequences. It also takes into account the proactive policy of the government in preventing internal migration. A general equilibrium matching model is developed and calibrated to replicated the relevant statistics that describe the main facts of the Italian labor markets. The model is used to explain the large unemployment gap between the North and the South of Italy, and at the same time the low wage productivity ratios paid to northern workers compared to the average in the other large western European countries. The model is based on three main pillars that determine the long run equilibrium. First of all, the centralized unions that set a wage, following a right to manage bargaining model, which is uniform across all regions. Second, a productivity divide that makes southern regions structurally less productive than the north. Finally, an active role of the government that aims at preventing the mass migration phenomenon that has characterized Italy until the mid seventies, by transferring resources from the north to the south targeting especially unemployment. A key feature of the model is that unions "move" first with respect to the government in setting the wage rate. Therefore, they take into account the tax rate that the government sets to collect the necessary resources to sustain unemployed workers and prevent migration. Because the wage rate is the same across regions, firms in the 
lower productive regions will tend to employ less workers, inducing higher unemployment while firms in higher productive regions will employ more workers and generate less unemployment. Moreover, because unions care about the tax rate as well as the wage rate, they will avoid setting a wage that is to high generating too much unemployment in the lower productive regions. This mechanism explains not only the large gap between the unemployment in the more productive north and the less productive south, but, especially, the low unemployment in the north as compared to other European countries with similar levels of productivity and labor regulations together with the the lower wages. The centralized wage and the commitment of the government to contain internal migration generates a political-economy equilibrium in which the lower productive south mitigates the unions' power to set high wages. A counterfactual experiments with decentralized unions shows this feature of the model. By allowing unions to set wages at the local level, a much expected political reform in Italy, the model predicts that wages would increase substantially in the north and decrease in the south, accordingly unemployment would increase in the north at levels comparable to other European countries and would decrease in the south at similar levels. 


\section{References}

Blanchard, Olivier Jean and Peter Diamond, "The Beveridge Curve," Brookings Papers on Economic Activity, 1989, 0 (1), 1-60. and __ , The Aggregate Matching Function Growth/Productivity/Unemployment: Essays to celebrate Bob Solow's birthday, Cambridge, Mass. and London: MIT Press, Festschrift honoree: Solow, Robert.

Brandolini, A., "The Distribution of Personal Income in Post-War Italy: Source Description, Data Quality, and the Time Pattern of Income Inequality," Temi di discussione, Banca D'Italia, 1999, (350).

Checchi, Daniele, "Trade union membership: theories and evidence for Italy," Lavoro e Relazioni Industriali, 2000, (Vol 2).

Cinanni, Paolo, Emigrazione e unit operaia. Un problema rivoluzionario (Emigration and workers' unity. A revolutionary problem), Feltrinelli, Milano, 1974.

Faini, R., "Trade Unions and Regional Development," European Economic Review, 1999, 42.

Faini, Riccardo, Giampaolo Galli, Pietro Gennari, and Fulvio Rossi, "An empirical puzzle: Falling migration and growing unemployment differentials among Italian regions," European Economic Review, 1997, 41.

Manacorda, M. and B. Petrongolo, "Regional Mismatch and Unemployment: Theory and Evidence from Italy, 1977-1998," Journal of Population Economics, 2005, (forthcoming 2005).

Mortensen, Dale T. and Christopher Pissarides, "New Developments in Models of Search in the Labour Market," CEPR, 1999, (DP.2053).

Nicoletti, Giuseppe, Stefano Scarpetta, and Olivier Boylaud, "Summary Indicators of Product Market Regulation with an Extension to Employment Protection Legislation," OECD Economics Department Working Papers, 1999. 
Rella, Piera and Titta Vadala, "Sociological Literature on Migration in Italy," Current Sociology, 1984, 32 (2), 143-174.

SVIMEZ, 2001 Report on the Economy of Southern Italy, Rome, Italy: Associazione per lo Sviluppo dell'Industria nel Mezzogiorno, 2001.

Viviano, E., "Unanalisi critica delle definizioni di disoccupazione e partecipazione in Itala," Banca d'Italia, July 2002. 


\section{Appendix A More Derivations}

This appendix shows how equation (4) can be derived. Notice that equation (3) can be written as follows

$$
r J_{i}(\alpha)=p_{i} \alpha-w+\lambda \int_{R_{i}}^{\bar{\alpha}} J_{i}(x) d F(x)-\lambda J_{i}(\alpha) .
$$

Also note that the integral on the right hand side represents already the conditional expectation of the match to an employer that is indicated with $J^{e}$. Therefore taking the conditional expectation of the whole expression it is possible to write

$$
\begin{array}{r}
\int_{R_{i}}^{\bar{\alpha}} r J_{i}(\alpha) d F(\alpha)=\int_{R_{i}}^{\bar{\alpha}}\left(p_{i} \alpha-w\right) d F(\alpha)+\int_{R_{i}}^{\bar{\alpha}}\left[\lambda \int_{R_{i}}^{\bar{\alpha}} J_{i}(x) d F(x)\right] d F(\alpha)- \\
\int_{R_{i}}^{\bar{\alpha}} \lambda J_{i}(\alpha) d F(\alpha) .
\end{array}
$$

That is

$$
r J_{i}^{e}=p_{i} \int_{R_{i}}^{\bar{\alpha}} \alpha d F(\alpha)-w+\lambda \int_{R_{i}}^{\bar{\alpha}} J_{i}(x) d F(x) \int_{R_{i}}^{\bar{\alpha}} d F(\alpha)-\lambda J^{e},
$$

and since the second integral on the right hand side is fact $J^{e}$, making use of equation (5) is possible to write

$$
r J_{i}^{e}=p_{i} \alpha^{e}-w+\lambda\left[1-F\left(R_{i}\right)\right] J^{e}-\lambda J^{e}
$$

which gives equation (4).

To understand equation (7) it is possible to think about the problem in a different way. When the meeting between the employer and the unemployed worker takes place, they draw from the $F(\alpha)$ distribution a number, but they know at this point only if it is greater or equal than $R_{i}$ or lower. Later they draw another value from the distribution that contains only numbers greater than $R_{i}$ if the first draw was greater, or lower if it was lower. They get $R_{i}$ again if they got $R_{i}$ in the first place. Equation (7) can then be written as follows:

$$
r V_{i}=-p_{i} c+q\left(\theta_{i}\right)\left[\int_{R_{i}}^{\bar{\alpha}}\left[\int_{R_{i}}^{\bar{\alpha}} J_{i}(x) d F(x)-V_{i}\right] d F(\alpha)\right]
$$


where the first part of the integral between the interval $\left[a, R_{i}\right]$ is dropped because it is equal to zero since $J_{i}(\alpha)$ equals zero for any value lower than $R_{i}$. Solving the double integral obtain equation (7) is obtained.

\section{Appendix B Solutions}

To solve the model the first step is to find a solution for the reservation values of the shocks as functions of the wage. First equation (3) is rewritten as follows

$$
(\lambda+r) J_{i}(\alpha)=p_{i} \alpha-w+\lambda \int_{R_{i}}^{\bar{\alpha}} J_{i}(x) d F(x) .
$$

Following Pissarides (2000) equation (22), for $\alpha=R_{i}$, becomes

$$
(\lambda+r) J_{i}\left(R_{i}\right)=p_{i} R_{i}-w+\lambda \int_{R_{i}}^{\bar{\alpha}} J_{i}(x) d F(x) .
$$

Subtracting equation (23) from equation (22), and noting that $J_{i}\left(R_{i}\right)=0$ it is possible to obtain

$$
(\lambda+r) J_{i}(\alpha)=p_{i}\left(\alpha-R_{i}\right)
$$

Now plugging equation (24) into equation (22) the following equation is obtained

$$
R_{i}=\frac{w}{p}-\frac{\lambda}{r+\lambda} \int_{R_{i}}^{\bar{\alpha}}\left(x-R_{i}\right) d F(x),
$$

and knowing the distribution $F(x)$ equation (25) can be solved obtaining $R_{i}$ as function of $w$.

Once the $R_{i}$ 's are found, the next step is to obtain the $\theta_{i}$ 's as a functions of $w$. To do so first a solution for the expected value of a match to an employer must be found. Given the free entry condition $V_{i}=0$, from equation (7) it is possible to write

$$
J_{i}^{e}=\frac{p_{i} c}{q_{i}^{f}} .
$$

Inserting equation (26) into equation (4) it is possible to obtain 


$$
\frac{p_{i} c}{q_{i}^{f}}=\frac{p_{i} \alpha_{i}^{e}-w}{r+\lambda F\left(R_{i}\right)}
$$

which can be solved for $\theta$ in terms of $w$, once the solution for $R_{i}$ is plugged into it .

Once the $R_{i}(w)$ 's and the $\theta_{i}(w)$ 's are found, these functions are plugged into the government objective functions to obtain $t(w)$ and $b(w)$. Finally plugging the solutions as functions of $w$ into the value of a job to a worker in the North, the objective function of the unions is obtained. Therefore, the solution for $w$ is obtained by maximizing this objective function. Once $w$ is found, all of the other parameters are also found.

\section{Appendix C Letter from A. Minucci former Secretary of the Italian Communist Party of Turin.}

\section{Appendix C.1 Original in Italian}

La necessit di arrestare l'esodo dei lavoratori meridionali e delle loro famiglie dal Sud verso il Nord,e soprattutto verso l'area torinese, fu posta per la prima volta come una questione sociale e politica fondamentale al XII congresso del Pci di Torino (febbraio 1972) nel rapporto introduttivo del segretario della Federazione comunista Adalberto Minucci.

Nel decennio 1950-60 la Fiat aveva registrato una espansione rapida e incontrollata. La popolazione di Torino era aumentata da 700 mila a 1 milione e trentamila abitanti. La congestione dell'area torinese aveva raggiunto limiti intollerabili, e per la stessa azienda automobilistica il vantaggio di una manodopera a basso prezzo si era trasformato in aumento di costi e in contraddizioni insuperabili. Tutti i servizi sociali, dalla scuola ai trasporti, alle fognature dei nuovi quartieri, versavano in una crisi sempre pi acuta .

La proposta dei comunisti di compiere una svolta radicale, spostando nelle regioni meridionali gli investimenti per le nuove fabbriche di automobili e i relativi servizi, fu discussa in varie riunioni riservate tra l'amministratore della Fiat Umberto Agnelli, il suo consigliere culturale ( lo scrittore Paolo Volponi che divenne poi senatore del Pci) e lo stesso responsabile del Pci torinese, Minucci. Le contraddizioni erano giunte a tal punto che i dirigenti della Fiat finirono per accogliere le proposte del Pci a lungo respinte. Per la prima volta una vertenza sindacale, apertasi in quel periodo, si pose il problema degli investimenti al Sud. Negli anni 
successivi sorsero le fabbriche automobilistiche di Melfi, di Termini Imerese, le fabbriche di macchine agricole in Puglia

\section{Appendix C.2 Translation}

The necessity to stop the exodus of Southern workers and their families from the South to the North, especially to the Turin area, was posed for the first time as a fundamental social and political issue at the XII congress of the PCI of Turin (February 1972) in its the introductory speech by the secretary of the communist Federation Adalberto Minucci.

Between 1950 and 1960 Fiat saw a rapid and uncontrolled growth. The population of Turin increased between 700,000 to one million and thirty thousand inhabitants. The congestion of the Turin area reached intolerable levels, and even for the automobile company the gain in terms of cheap labor vanished bringing higher costs and insuperable contradictions. All social services, from school to transportation, sewage for new city areas, were in a very acute crisis.

The proposal of the communists to perform a radical change, re-directing the investments for new factories of automobiles and the relative services to the southern regions of Italy, was discussed in several meetings between the CEO of Fiat Umberto Agnelli, his cultural counselor (Paolo Volponi, writer, who later became senator for PCI) and the secretary of PCI in Turin, Minucci. The problems were at such a level that the head of Fiat accepted the proposals of PCI which refused in the past. For the first time in a dispute opened in that period by the unions, the problem of investing in the South was posed. In the following years factories of automobiles in Melfi, Termini Imerese were opened and factories of agriculture machinery in Puglia were also opened. 


\section{Appendix D Additional Figures}

Figure D1: Capital per Working Unit - S/N Ratio

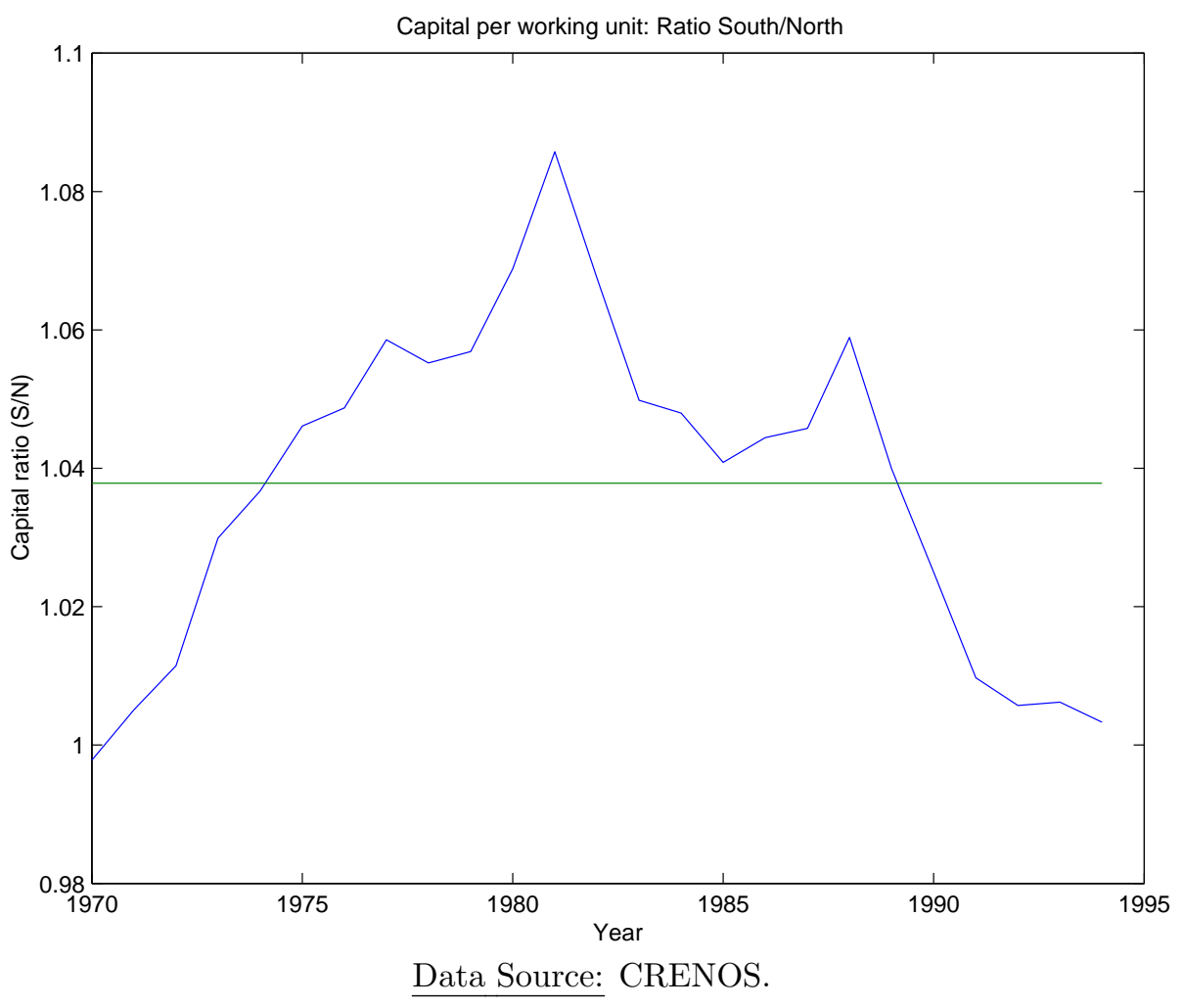


Figure D2: Productivity and Capital per Unit - S/N Ratio
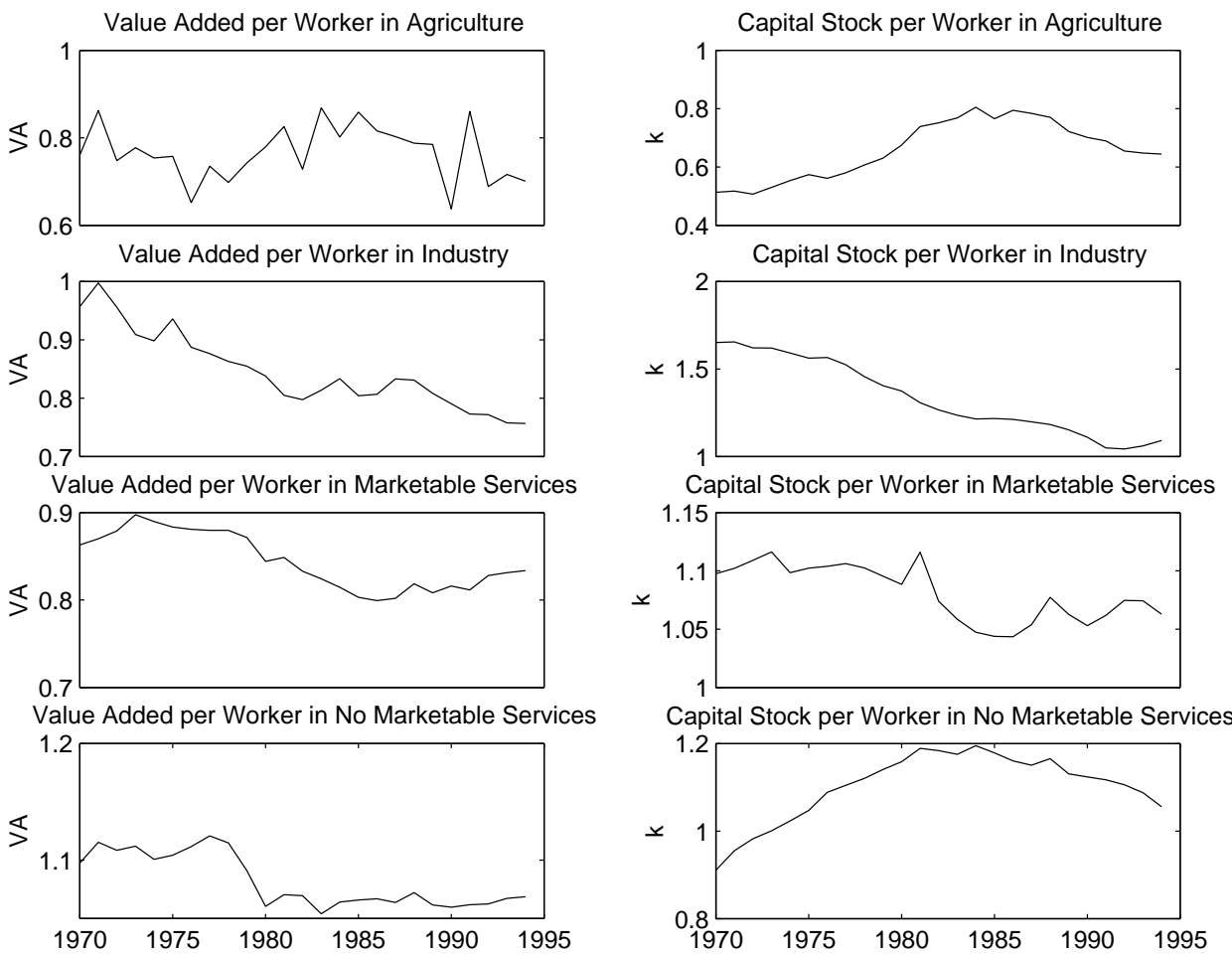

Data Source: CRENOS. 
Figure D3: Productivity - S/N Ratio

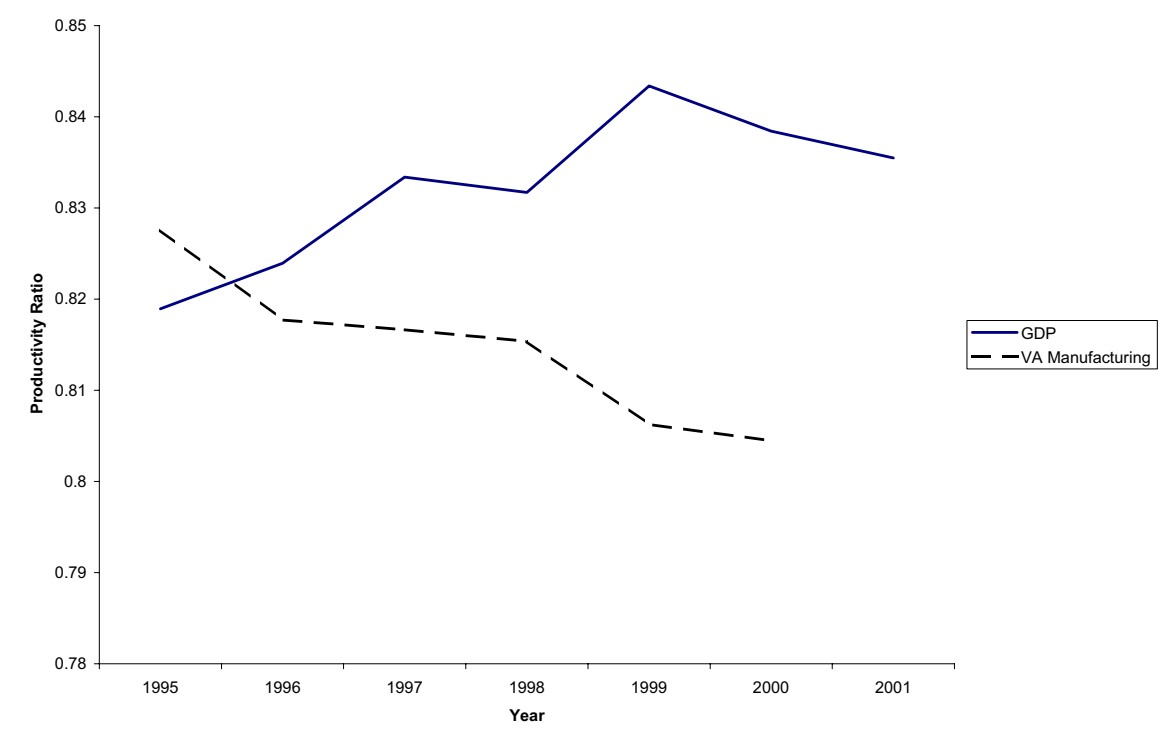

Data Source: ISTAT. 